\title{
Effects of Reduced Oxygen and Glucose Levels on Ocular Cells in vitro: Implications for Tissue Models
}

\author{
Edward A. Sander ${ }^{\mathrm{a}-\mathrm{c}}$ Eric A. Nauman ${ }^{\mathrm{b}-\mathrm{d}}$

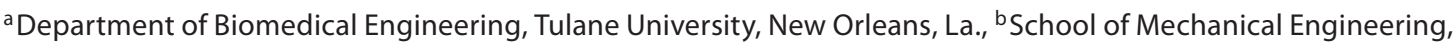 \\ 'Weldon School of Biomedical Engineering and d Department of Basic Medical Sciences, Purdue University, \\ West Lafayette, Ind., USA
}

\section{Key Words}

Aerobic cell metabolism • Anaerobic metabolism • Glaucoma S Sclera $\cdot$ Lamina cribrosa $\cdot$ Fibroblasts · Astrocytes

\begin{abstract}
An important goal of tissue engineering is the development of better in vitro tissue models for the study and treatment of diseases, especially those that are difficult to model in animals, such as glaucoma. In order to properly interpret experimental results designed to mimic in vivo conditions, it is necessary to characterize the metabolic state of the in vitro culture. The goal of this study was to determine how porcine lamina cribrosa cells (PLC), porcine scleral fibroblasts (PSC) and rat astrocytes (RAS) respond metabolically to reduced glucose and oxygen levels compared to normal in vitro culture conditions. Throughout the culture period, cell number and the levels of glucose, lactate, pyruvate and glutamate were characterized. Cell number in the PLC and PSC was more sensitive to glucose level than oxygen, while the RAS exhibited sensitivities to both variables. While the pyruvate and glutamate levels did not vary substantially between groups, glucose consumption and lactate production were dependent on culture condition. In addition, the $\Delta \mathrm{L} / \Delta \mathrm{G}$ ratio was dependent on glucose and oxygen levels, but not cell
\end{abstract}

type at early time points. By day 7, however, the RAS exhibited ratios consistently lower than the other cell types. The results of this study serve as a basis for future studies into the degenerative matrix remodeling in the glaucomatous optic nerve head, and may prove insightful for other tissue engineering applications.

Copyright $\odot 2009$ S. Karger AG, Basel

\section{Introduction}

Tissue engineering is an expanding field that seeks not only to produce functional tissue replacements but also to improve all cell-based technologies and their myriad applications. One such application is the development of

\section{Abbreviations used in this paper}

ANOVA analysis of variance

DMEM Dulbecco's modified Eagle medium

PLC porcine lamina cribrosa cells

PSC porcine scleral fibroblasts

RAS rat astrocytes

TCA tricarboxylic acid cycle

\section{KARGER}

Fax +4161306 1234

E-Mail karger@karger.ch

www.karger.com (c) 2009 S. Karger AG, Basel

Accessible online at: www.karger.com/cto
Dr. Eric A. Nauman

School of Mechanical Engineering

Purdue University, 585 Purdue Mall

West Lafayette, IN 47907-2088 (USA)

Tel. +1 765494 8602, Fax +1 765494 0539, E-Mail enauman@purdue.edu 
better in vitro tissue models for the study and treatment of disease [Griffith and Naughton, 2002; Sivaraman et al., 2005; Tjabringa et al., 2008]. For example, tissue engineering strategies have been adopted to investigate mechanical loading of bone cells to understand what cues stimulate bone growth [Shimko et al., 2003; Ignatius et al., 2005], to create blood vessel analogues for preclinical evaluations of stent endothelialization [Cardinal et al., 2006] and to evaluate toxicity using innervated corneal constructs [Suuronen et al., 2004]. Another area of exploration, both in terms of reproducing the physiological and pathophysiological environment, is the development of low oxygen and nutrient models, such as in the study of healing ligaments [Fermor et al., 1998], cartilage [Hansen et al., 2001] and hepatocyte transplantation [Smith and Mooney, 2007]. The study of glaucomatous degeneration of the optic nerve head is also well suited for this type of model [Burgoyne et al., 2005].

Glaucoma is an optic neuropathy characterized by a classic pattern of visual field loss and excavation of the optic nerve head [Burgoyne et al., 2005]. One aspect of glaucomatous damage to the optic nerve head neural and connective tissue may be a cell-mediated response to decreased nutrient and oxygen levels [Hernandez et al., 1989; Hernandez, 2000; Burgoyne et al., 2005]. Intraocular pressure-related stress and strain may directly and indirectly limit nutrient and oxygen levels through a variety of mechanisms, including tissue compression, reduced blood flow within the prelaminar and laminar capillaries as well as altered connective tissue over the life of the patient and within the stages of the disease [Burgoyne et al., 2005]. The support cells of the optic nerve head, including astrocytes, lamina cribrosa cells and fibroblasts, may respond to this change in environment by producing chemical factors that remodel the surrounding connective tissue and damage and eventually kill the axon bundles contained within [Hernandez, 2000]. Additional potential modes of injury include sudden mechanical failure of the supporting connective tissue and acute or chronic ischemic conditions that arise from adverse pressure gradients [Bellezza et al., 2000].

To model this form of connective tissue damage, we are developing an in vitro mimic of the optic nerve head using tissue engineering principles. Such a model will provide a means to investigate the cell response to nutrient and limited oxygen conditions. As part of this effort, we have found that it is first important to understand how the in vitro experimental conditions relate to the in vivo environment. Many cell types switch to anaerobic-dominated respiration from their normal in vivo aerobic state when cultured [Brand, 1997; Gstraunthaler et al., 1999; Freshney, 2000]. In order to properly interpret experimental results designed to mimic in vivo conditions, particularly those involved in cellular metabolism, it is first necessary to characterize the metabolic state of the in vitro culture. Consequently, the purpose of this study was to determine how porcine lamina cribrosa cells (PLC), porcine scleral fibroblasts (PSC) and rat astrocytes (RAS) respond metabolically to reduced glucose and oxygen levels compared to normal in vitro culture conditions. In vivo oxygen concentrations are much lower than $21 \% \mathrm{O}_{2}$ routinely used. The average concentration of oxygen in tissues is $3 \%$ [Csete, 2005]. In the optic nerve head, the oxygen tension ranges between $10 \mathrm{~mm} \mathrm{Hg}\left(1.3 \% \mathrm{O}_{2}\right)$ and $50 \mathrm{~mm} \mathrm{Hg}\left(6.6 \% \mathrm{O}_{2}\right)$ in a manner dependent on proximity to the vasculature and the perfusion pressure [Stefansson et al., 2005a, b]. In this study, we examined how ocular cells cultured under low oxygen $\left(1 \% \mathrm{O}_{2}\right)$ respond to glucose-limiting conditions that might occur in the pathophysiology of glaucomatous damage to the optic nerve head. Ocular cells were also examined under $21 \%$ $\mathrm{O}_{2}$ to provide a baseline for comparison with other studies. The results of this study serve as a basis for future studies into the degenerative matrix remodeling in the glaucomatous optic nerve head, and may prove insightful for other tissue engineering applications.

\section{Materials and Methods}

\section{Cell Sources}

Cells from porcine optic nerve heads and sclera were harvested from eyes obtained within $6 \mathrm{~h}$ of death from a local slaughter house. During each stage of the dissection, tissue was transferred to a tissue culture dish containing $15-20 \%$ penicillin-streptomycin and $7.5-10 \%$ amphotericin B in phosphate-buffered saline (PBS) to prevent bacterial and fungal contamination. Each eye was cleaned of the surrounding tissue. The optic nerve was severed near the base of the sclera and the nerve head removed with a $4-\mathrm{mm}$ biopsy punch. The perimeter and posterior face of each optic nerve head was carefully trimmed with a scalpel blade to minimize cell contamination from surrounding tissues. The remaining optic nerve head tissue was diced into smaller pieces and transferred to T-25 tissue culture flasks containing $6 \mathrm{ml}$ of sterile filtered digestion media, consisting of $3 \mathrm{mg} / \mathrm{ml}$ collagenase type I (Sigma, St. Louis, Mo., USA) in Dulbecco's modified Eagle medium (DMEM; Invitrogen, Carlsbad, Calif., USA) supplemented with 10\% FBS and 1\% Ab/Am (Sigma). Scleral strips were also sectioned and the choroid was removed before transfer to T-25 tissue culture flasks also containing $6 \mathrm{ml}$ of digestion medium. Tissue explants were digested overnight in a humidified incubator set at $5 \% \mathrm{CO}_{2}$ with the remainder air $\left(21 \% \mathrm{O}_{2}\right)$ and $37^{\circ} \mathrm{C}$. The following morning, the contents of each flask were passed through a 100$\mu \mathrm{m}$ cell strainer, centrifuged and washed with PBS 3 times, and 
resuspended into T-25 tissue culture flasks containing $6 \mathrm{ml}$ of DMEM supplemented with $10 \% \mathrm{FBS}$ and $1 \% \mathrm{Ab} / \mathrm{Am}$.

Due to the difficulty of harvesting ocular astrocytes from porcine tissue, another cell source was found. Immortalized rat astrocytes derived from neonatal Sprague-Dawley brains were purchased from ATCC (ATCC No. CRL-2005). Rat astrocytes were expanded in DMEM supplemented with $10 \%$ FBS and $1 \% \mathrm{Ab} / \mathrm{Am}$. These cells were used both for phenotypic identification and comparison with tissue-derived lamina cribrosa cells and scleral fibroblasts.

\section{Experimental Culture Conditions}

Scleral fibroblasts and lamina cribrosa cells were plated for experiments between the 2 nd and 5 th passages, respectively, in 24-well tissue culture plates at a cell seeding density of 100,000 cells per well. Cells were passaged with a $0.25 \%$ Trypsin/EDTA solution (Invitrogen). Rat astrocytes were plated at the 18th passage at the same density. Each well was made to a final volume of $1 \mathrm{ml}$ of DMEM containing 10\% FBS and 1\% Ab/Am, $5.5 \mathrm{~mm}$ glucose, $4 \mathrm{~mm}$ glutamate and $1 \mathrm{~mm}$ sodium pyruvate. All plates were incubated for $24 \mathrm{~h}$ in a humidified incubator under normal cell culture conditions of $37^{\circ} \mathrm{C}, 5 \% \mathrm{CO}_{2}$ and $21 \% \mathrm{O}_{2}$ (95\% air) for the purpose of allowing the cells to attach and equilibrate. Immediately, after the $24 \mathrm{~h}$ equilibrium period, medium was removed and the wells rinsed twice with $1 \mathrm{ml}$ of PBS. To each well, $1 \mathrm{ml}$ of either high or low glucose medium was added ( 3 for each cell type and medium formulation, see below). Plates were transferred to either a humidified culture chamber maintained at $37^{\circ} \mathrm{C}, 5 \% \mathrm{CO}_{2}$ and $1 \% \mathrm{O}_{2}$ or an incubator maintained under normal cell culture conditions of $37^{\circ} \mathrm{C}, 5 \% \mathrm{CO}_{2}$ and $21 \% \mathrm{O}_{2}$. Plates were removed after 12 h, 1 day, 3 days and 7 days.

Two formulations of DMEM, both supplemented with $10 \%$ FBS and $1 \% \mathrm{Ab} / \mathrm{Am}$, were used in this experiment. Our high glucose formulation was Invitrogen/Gibco low glucose DMEM (catalog No. 11885) containing 1,000 mg/l of D-glucose, $584 \mathrm{mg} / \mathrm{l}$ of L-glutamine and $110 \mathrm{mg} / \mathrm{l}$ sodium pyruvate. This corresponds to $5.5,4$ and $1 \mathrm{~mm}$ concentrations, respectively. Our rationale was that in vivo blood glucose concentrations are on the order of $5 \mathrm{mM}$ [Foster and Rubenstein, 1994] and the tissue levels are likely even lower. Our low glucose formulation was sterile-filtered Invitrogen/Gibco no glucose DMEM (catalog No. 11966) containing $584 \mathrm{mg} / \mathrm{l}$ of L-glutamine to which $100 \mathrm{mg} / \mathrm{l}$ of D-glucose and $110 \mathrm{mg} / \mathrm{l}$ of sodium pyruvate were added. The addition of $10 \%$ FBS increased the total amount of glucose in the medium to $1.26 \mathrm{mM}$. Plates were assayed at $12 \mathrm{~h}, 1$ day, 3 days and 7 days with no medium exchange for the duration of the experiment.

Low oxygen levels in the gas phase were achieved with a commercial low oxygen system (Biospherix Ltd., Redfield, N.Y., USA). An independently regulated culture chamber was contained within an incubator that provided temperature control and was maintained at $37^{\circ} \mathrm{C}$. Two ProOx controllers regulated the gas phase; one maintained the $\mathrm{CO}_{2}$ level at $5 \%$ and the other the oxygen level at $1 \%$ through nitrogen control.

\section{Cell Number}

Cell number was determined using a Hoechst 33342 fluorometric assay [Richards et al., 1985; Blaheta et al., 1991]. Briefly, wells were rinsed twice with PBS, and $500 \mu$ l of Hoechst staining solution consisting of serum-free DMEM and containing $4 \mu \mathrm{g} / \mathrm{ml}$ Hoechst 33342 was added to each well. Plates were incubated for
$90 \mathrm{~min}$ and the fluorescence was measured at an excitation and emission wavelength of 355 and $460 \mathrm{~nm}$, respectively. The fluorescence from each well was then converted to cell number based on predetermined standards curves. Cell number was measured at all time points including the initial time point.

\section{Metabolite Measurements}

Medium glucose and glutamate levels were measured fluorometrically with an Amplex ${ }^{\circledR}$ Red Glucose/Glucose Oxidase kit (Invitrogen/Molecular Probes, Carlsbad Calif., USA) and Amplex ${ }^{\circledR}$ Red Glutamic Acid/Glutamate Oxidase Assay kit. Lactate medium levels were measured with an L-lactic acid assay kit (R-Biopharm, Darmstadt, Germany). Pyruvate concentrations were also determined by employing a well-developed enzymatic assay [Bergmeyer, 1983; Planchet et al., 2005].

\section{Statistical Analysis}

Statistical significance was determined using either a 1- or 2factor analysis of variance (ANOVA) with a significance level of $p<0.05$. Student-Newman-Keuls post hoc tests were applied where the outcome of an ANOVA indicated significance. Statistical analysis was conducted with StatView statistical software (SAS Institute, Cary, N.C., USA).

\section{Results}

\section{Cell Proliferation}

PSC cells remained confluent for most culture conditions except the combination of $1 \% \mathrm{O}_{2}$ and low glucose which resulted in substantial cell death by day 3 (fig. 1). Similar trends for the culture conditions were observed for PLC cells. The RAS cells exhibited a higher proliferation rate over a 7-day period, with cell death appearing in the $1 \% \mathrm{O}_{2}$ and low glucose group by day 1 .

During the 24-hour seeding period, cell numbers for all 3 cell types increased from the initial cell seeding density of 100,000 cells per well. Cell numbers at $\mathrm{t}=0$ were $230,000 \pm 15,000,420,000 \pm 30,000$ and 160,000 \pm 40,000 cells per well for PLC, RAS and PSC cells, respectively. Maximum cell numbers occurred at day 3 in high glucose medium and were 390,000 \pm 40,000, 2,070,000 $\pm 300,000$ and $280,000 \pm 100,000$ cells per well for PLC, RAS and PSC cells, respectively.

PLC cell number (fig. 2) was dependent on the initial glucose levels of the medium $(p<0.0001)$ but not on the oxygen tension ( $\mathrm{p}=0.290$ ), as indicated by a 2 -factor ANOVA with time as a covariate. In high glucose medium, cell number increased to nearly 400,000 cells per well at day 3 for both oxygen levels. Cell number declined at day 7 , particularly for cells in $1 \% \mathrm{O}_{2}$ as evidenced in the micrograph (fig. 3). Day 7 cells exposed to $21 \% \mathrm{O}_{2}$ visually showed no signs of decrease, an observation within 


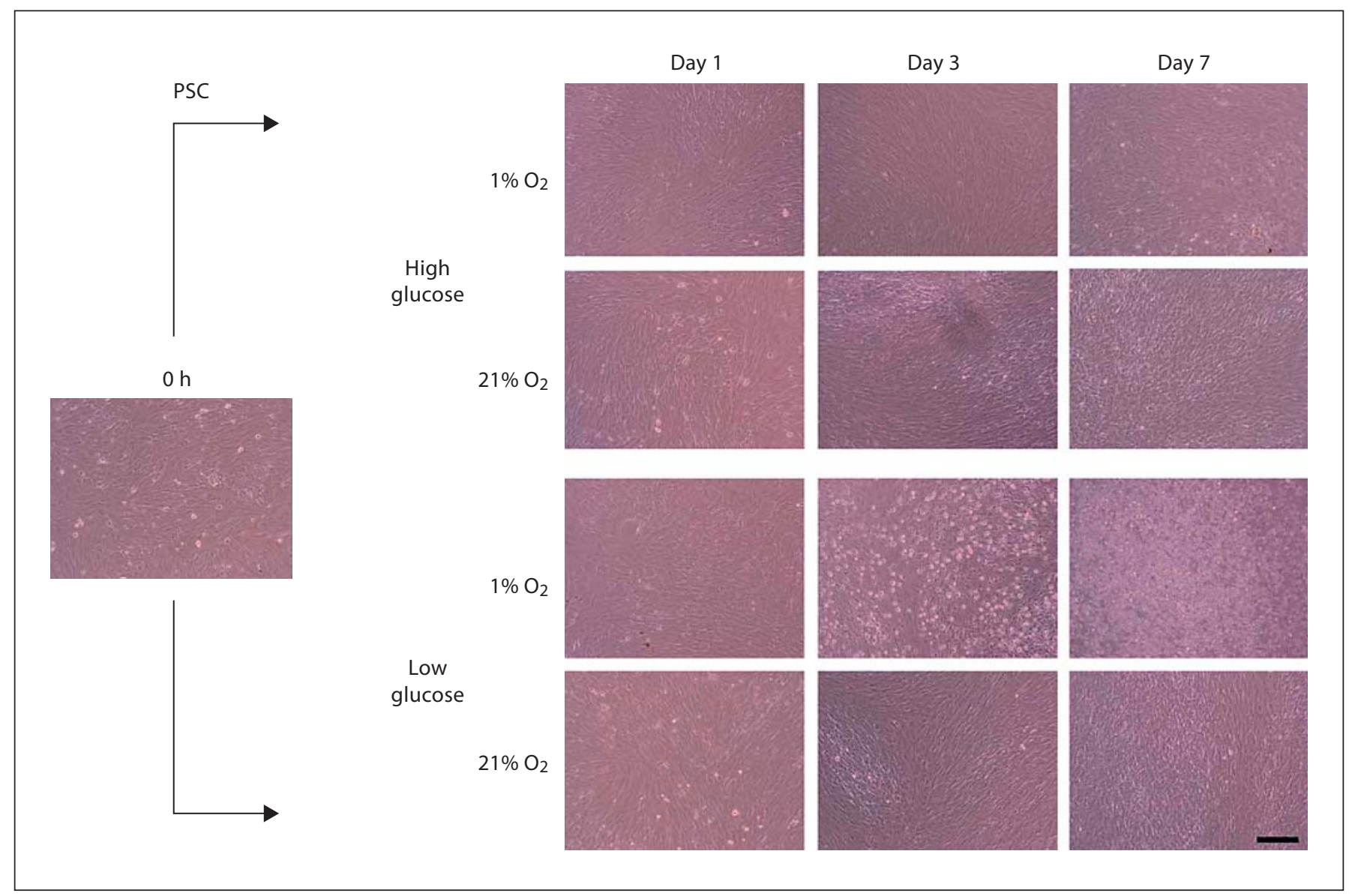

Fig. 1. Representative phase contrast micrographs for all culture conditions over 1 week. PSC cells remained confluent for most culture conditions. The combination of $1 \% \mathrm{O}_{2}$ and low glucose resulted in substantial cell death by day 3. Similar trends for the culture conditions were observed for PLC and RAS cells. Scale bar = $250 \mu \mathrm{m}$.

the range of standard deviation but in opposition to the mean of the fluorometric measurement. In low glucose medium, cell number at $12 \mathrm{~h}$ decreased before increasing at day 1 to a maximum of 240,000 $\pm 10,000$ and 320,000 $\pm 10,000$ cells per well for 1 and $21 \% \mathrm{O}_{2}$, respectively. Cell number declined through day 7 to $71,000 \pm 15,000$ and $117,000 \pm 8,000$ cells per well for 1 and $21 \% \mathrm{O}_{2}$, respectively. A 1-factor ANOVA for oxygen at each time point revealed differences in high glucose medium at day $1(\mathrm{p}<0.01)$ and in low glucose medium at days $1(\mathrm{p}<$ $0.001)$ and $7(\mathrm{p}<0.01)$.

RAS cells followed similar trends as PLC cells (fig. 2). However, a 2-factor ANOVA with time as a covariate indicated that cell number was dependent on both glucose concentration $(\mathrm{p}<0.0001)$ and oxygen tension $(\mathrm{p}=$ 0.0012 ). Cell number was higher in high versus low glucose and in 21 versus $1 \% \mathrm{O}_{2}$. In high glucose medium, cell number increased through day 3 to a maximum of 1.2 and 2.1 million cells per well in 1 and $21 \% \mathrm{O}_{2}$, respectively. As with the PLC cells, cell number declined by day 7 , but more so for RAS cells in $1 \% \mathrm{O}_{2}$. In low glucose medium, cell number increased at day 1 to a maximum and then declined through day 7. Under $1 \% \mathrm{O}_{2}$ the increase was less and the decline greater than under $21 \% \mathrm{O}_{2}$. A 1factor ANOVA for oxygen at each time point showed a significant difference in high glucose medium at day 3 $(\mathrm{p}<0.01)$ and in low glucose medium at days 1,3 and 7 $(\mathrm{p}<0.001, \mathrm{p}<0.0001$ and $\mathrm{p}<0.0001$, respectively).

A 2-factor ANOVA indicated that PSC cell numbers were dependent on glucose $(\mathrm{p}=0.0014)$ but not oxygen $(\mathrm{p}=0.630)$. In high glucose medium, cell number increased to a maximum through day 3 and declined at day 7. In low glucose medium, maximum cell number occurred at day 1 and decreased through day 7. However, 


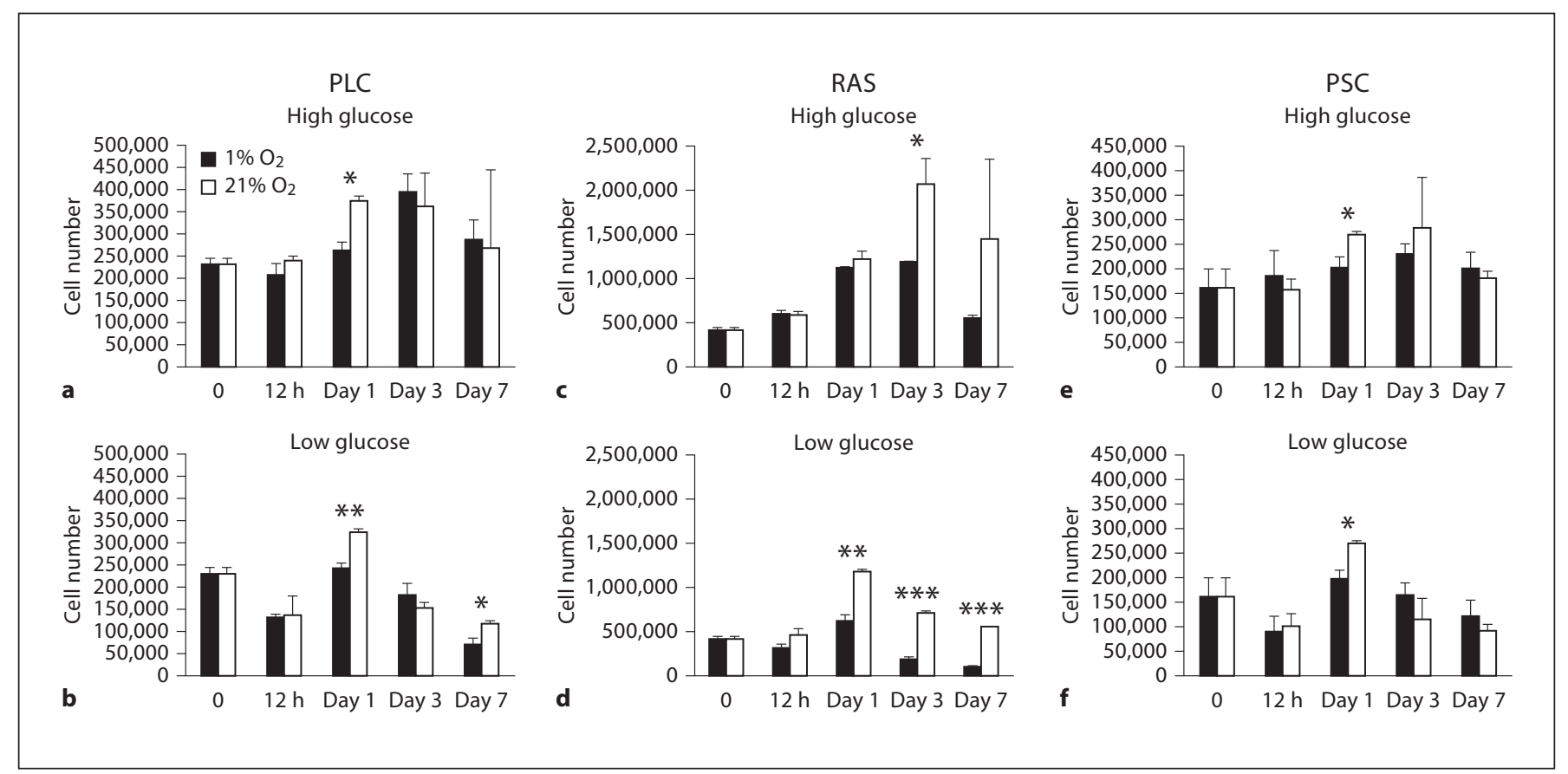

Fig. 2. Cell number in high glucose (a, c, e) and low glucose (b, d, f). PLC cell number (a, b), RAS cell number $(\mathbf{c}, \mathbf{d})$ and PSC cell number $(\mathbf{e}, \mathbf{f})$ at day 3 in high glucose medium and days 1, 3 and 7 in low glucose medium. ${ }^{*} \mathrm{p}<0.01 ;{ }^{* *} \mathrm{p}<0.001 ;{ }^{* * *} \mathrm{p}<0.0001$.

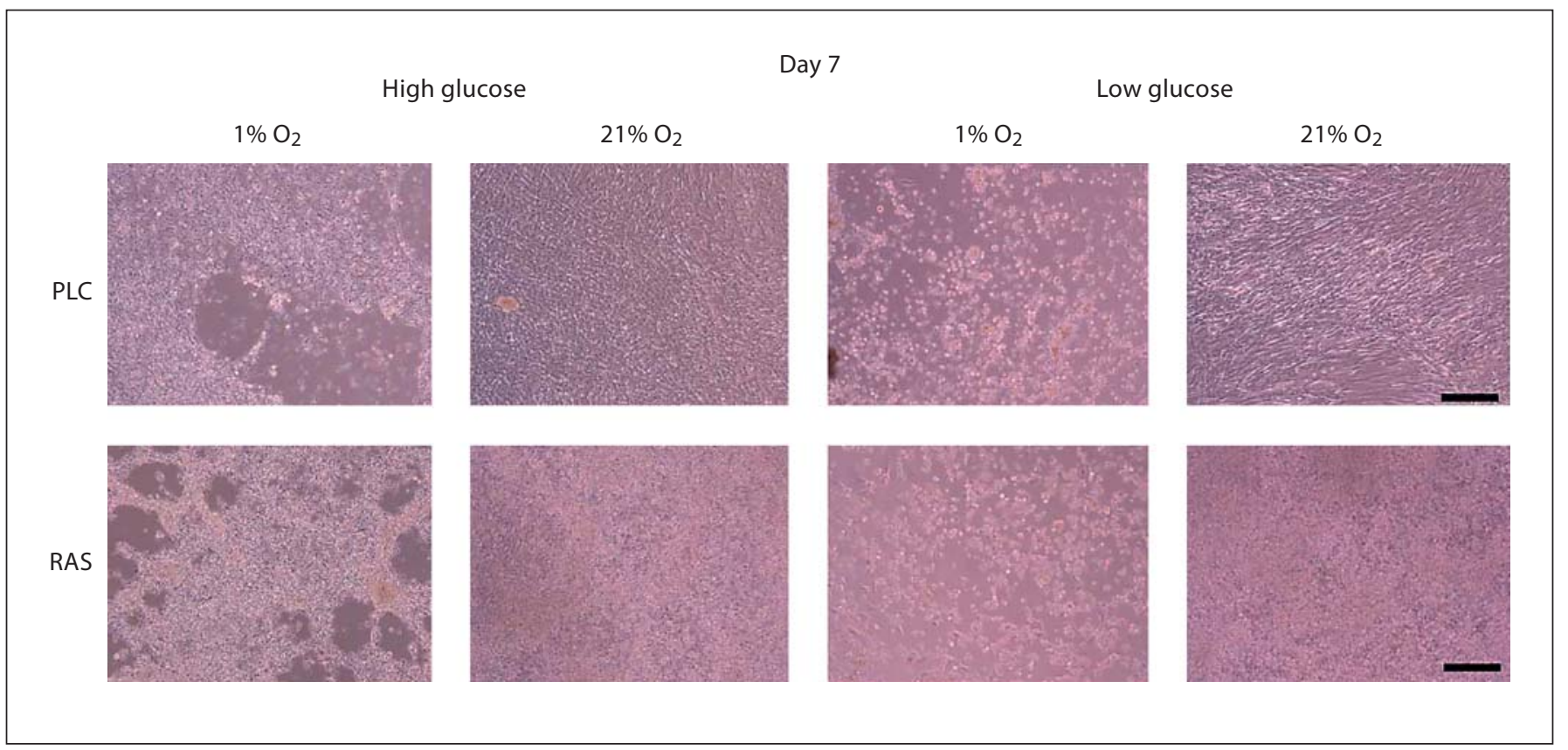

Fig. 3. Representative phase contrast micrographs for PLC and RAS cell groups at day 7. RAS cells, due to their higher proliferation rate, followed the pattern observed in PSC cells at an accelerated rate with cell death appearing in $1 \% \mathrm{O}_{2}$ and low glucose by day 1 . Scale bars $=250 \mu \mathrm{m}$. 


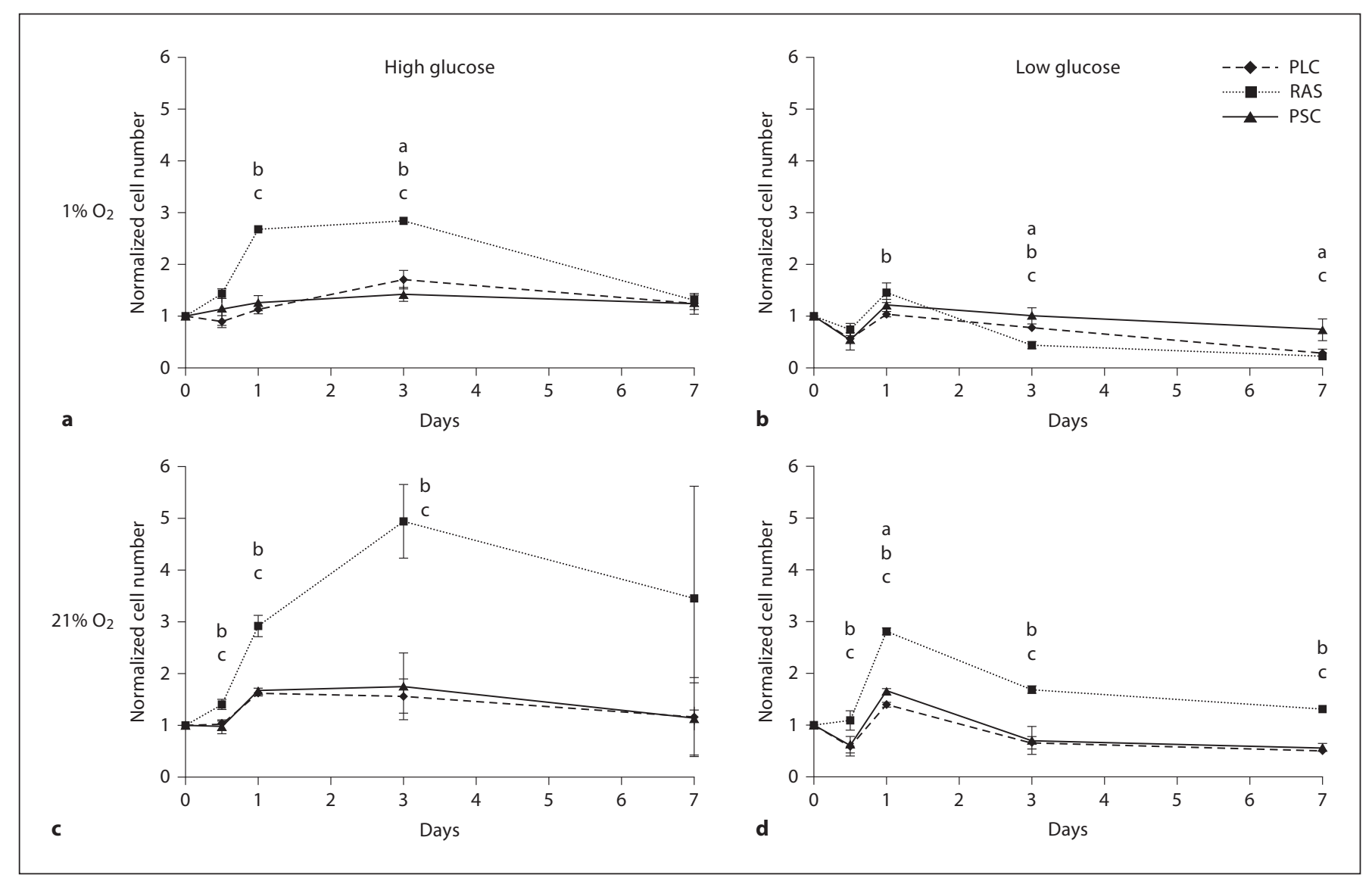

Fig. 4. Cell number at each time point was normalized to cell number at $\mathrm{t}=0: 1 \% \mathrm{O}_{2}$, high glucose $(\mathbf{a}) ; 1 \% \mathrm{O}_{2}$, low glucose (b); $21 \% \mathrm{O}_{2}$, high glucose (c); $21 \% \mathrm{O}_{2}$, low glucose (d). RAS proliferated to higher numbers than PLC or PSC. PLC and PSC cell proliferation was similar for all cases except at day 3 (a), day 1 (d) and at days 3 and 7 (b). A 1-factor ANOVA for cell type, followed by a Student-Newman-Keuls post hoc test, was performed at each time point for each of the 4 culture conditions. Significance $(\mathrm{p}<0.05)$ between cell type: ${ }^{a}$ PLC, PSC; ${ }^{b}$ RAS, PLC; ${ }^{c}$ RAS, PSC.

unlike the PLC and RAS cells, the decrease in cell number at day 7 under $1 \% \mathrm{O}_{2}$ was less severe as evidenced by both the micrographs (data not shown) and fluorometric data (fig. 2). A 1-factor ANOVA for oxygen at each time point demonstrated significance in both high and low glucose medium at day $1(\mathrm{p}<0.01)$.

Comparisons in cell number between the 3 cell types were conducted by normalizing cell number at each time point to the initial cell number measured at $t=0$ (fig. 4). A 1-factor ANOVA for a difference in cell type, followed by a Student-Newman-Keuls post hoc test, was conducted at each time point for all 4 culture conditions ( $\mathrm{p}<$ 0.05). Cell proliferation was more pronounced in RAS cells compared to PLC and PSC cells. For all 3 cell types, peak cell numbers were realized at day 3 in high glucose medium and at day 1 in low glucose medium, regardless of the oxygen levels. However, the magnitude of this increase did depend on the oxygen level for RAS cells. For most conditions, PLC and PSC growth trends were indistinguishable from each other. Significant differences $(\mathrm{p}<$ 0.05 ) coincided with peak cell number for $1 \% \mathrm{O}_{2}$, high glucose at day 3 and $21 \% \mathrm{O}_{2}$ low glucose at day 1 . In addition, significant differences occurred for $1 \% \mathrm{O}_{2}$ and low glucose at days 3 and 7.

\section{Metabolite Levels}

Glucose was consumed in a culture and cell type-dependent manner (fig. 5). PLC and PSC cells consumed glucose faster in 1 than $21 \% \mathrm{O}_{2}$. For PLC cells cultured in $1 \% \mathrm{O}_{2}$, glucose in the high glucose medium was depleted 


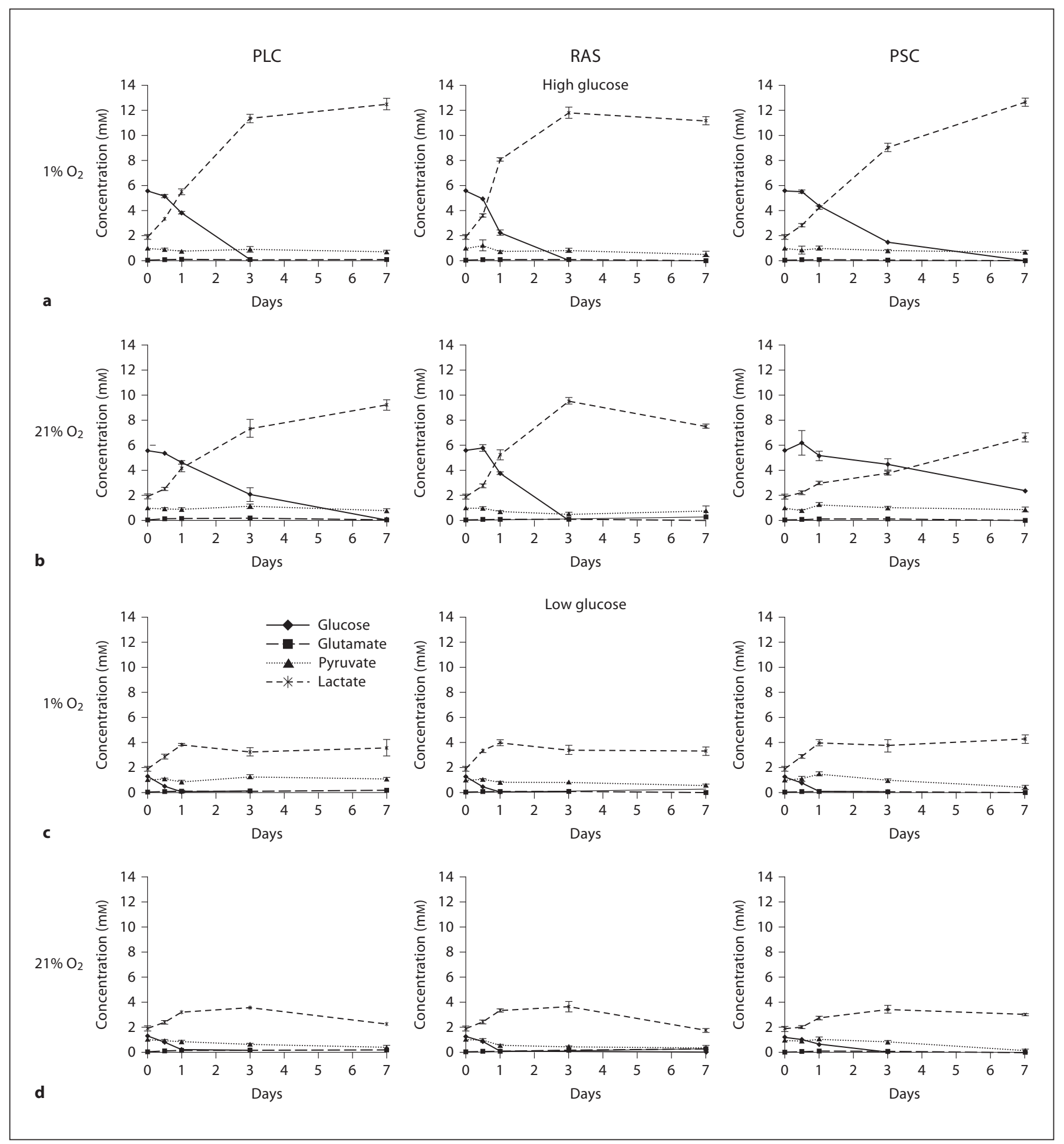

Fig. 5. Metabolites glucose, glutamate, pyruvate and lactate were measured during the experiment for each of 4 conditions: high glucose $1 \% \mathrm{O}_{2}(\mathbf{a})$, high glucose $21 \% \mathrm{O}_{2}(\mathbf{b})$, low glucose $1 \% \mathrm{O}_{2}$ (c) and low glucose $21 \% \mathrm{O}_{2}(\mathbf{d})$. $\mathrm{n}=3$ for each point. 
by day 3 . Under $21 \% \mathrm{O}_{2}, 2.05 \pm 0.55 \mathrm{~mm}$ glucose still remained at day 3; no glucose remained by day 7 . For low glucose medium, glucose was depleted by day 1 in $1 \% \mathrm{O}_{2}$ but $0.19 \pm 0.03 \mathrm{mM}$ remained in $21 \% \mathrm{O}_{2}$.

RAS glucose levels were exhausted by days 3 and 1 for high glucose and low glucose medium, respectively, for both oxygen levels. The data likely did not reflect an oxygen-dependent difference because the time interval between measurements did not have sufficient resolution due to higher rates of RAS proliferation and glucose consumption compared to the other 2 cell types.

PSC glucose levels followed similar trends to the PLC cells in that glucose was consumed at a slower rate at $21 \%$ $\mathrm{O}_{2}$ compared to $1 \% \mathrm{O}_{2}$. However, more glucose remained in the medium of PSC cells than in PLC cells at the same culture conditions and time points. In high glucose medium, and in $1 \% \mathrm{O}_{2}$, no glucose remained at day 7 (1.47 $\pm 0.05 \mathrm{~mm}$ remained at day 3 ). In $21 \% \mathrm{O}_{2}$, approximately $40 \%$ of the initial glucose, or $2.35 \pm 0.07 \mathrm{mM}$ glucose, still remained at day 7. Similarly, at day 1 virtually no glucose remained in low glucose medium in $1 \% \mathrm{O}_{2}$ but more than half the initial glucose $(0.68 \pm 0.03 \mathrm{mM})$ remained in $21 \% \mathrm{O}_{2}$.

Glutamate levels in the medium for all 3 cell types initially began at $0.37 \mathrm{mM}$ and decreased after $12 \mathrm{~h}$ to levels ranging between 0.06 and $0.11 \mathrm{~mm}$ (fig. 5). For the most part, the concentration of glutamate hovered around 0.1 $\mathrm{mM}$, fluctuating between 0.27 and $0 \mathrm{mM}$, over the course of the experiment. In $1 \% \mathrm{O}_{2}$, no glutamate was detected on day 7 in either high or low glucose medium for both RAS and PSC cells. For PSC cells in $21 \% \mathrm{O}_{2}$, no glutamate was found on day 7 in either medium formulation.

Pyruvate levels oscillated around $1 \mathrm{~mm}$, the initial medium concentration, for all 3 cell types (fig. 5). Pyruvate decreased by day 7 for all groups except PLC cells in $1 \%$ $\mathrm{O}_{2}$ and low glucose (1.08 \pm 0.11$)$. Of the 4 conditions, $21 \%$ $\mathrm{O}_{2}$ and low glucose resulted in the lowest pyruvate concentrations at day 7: $0.39 \pm 0.17,0.38 \pm 0.16$ and $0.18 \pm$ $0.12 \mathrm{mM}$ for PLC, RAS and PSC cells, respectively.

Lactate production was dependent on glucose levels and oxygen concentrations and followed similar patterns for all 3 cell lines (fig. 5). The amount of lactate produced at each time point coincided with the amount of glucose consumed, with the largest production rates occurring during periods with the highest glucose consumption. As expected, more lactate was produced in high glucose medium compared to low glucose medium. In addition, for the same initial glucose concentration, more lactate was produced in 1 than $21 \% \mathrm{O}_{2}$. Interestingly, in $21 \% \mathrm{O}_{2}$ lactate decreased at day 7 in low glucose medium for all 3
Table 1. $\Delta \mathrm{L} / \Delta \mathrm{G}$ ratio on days 1 and 7

\begin{tabular}{llllll}
\hline \multirow{2}{*}{$\begin{array}{l}\text { Cell } \\
\text { type }\end{array}$} & \multicolumn{2}{l}{ High glucose } & & \multicolumn{2}{l}{ Low glucose } \\
\cline { 2 - 3 } \cline { 5 - 6 } & $21 \% \mathrm{O}_{2}$ & $1 \% \mathrm{O}_{2}$ & & $21 \% \mathrm{O}_{2}$ & $1 \% \mathrm{O}_{2}$ \\
\hline Day 1 & & & & \\
PLC & $2.38 \pm 0.54$ & $2.07 \pm 0.21$ & & $1.22 \pm 0.20$ & $1.56 \pm 0.18$ \\
RAS & $1.82 \pm 0.27$ & $1.86 \pm 0.14$ & $1.21 \pm 0.21$ & $1.65 \pm 0.25$ \\
PSC & $2.46 \pm 2.21$ & $1.91 \pm 0.20$ & $1.49 \pm 0.44$ & $1.78 \pm 0.30$ \\
\hline Day 7 & & & & \\
PLC & $1.31 \pm 0.08$ & $1.90 \pm 0.09$ & $0.28 \pm 0.17$ & $1.31 \pm 0.55$ \\
RAS & $1.00 \pm 0.05$ & $1.66 \pm 0.07$ & $-0.13 \pm 0.20$ & $1.11 \pm 0.31$ \\
PSC & $1.46 \pm 0.13$ & $1.92 \pm 0.07$ & $0.91 \pm 0.17$ & $1.86 \pm 0.31$ \\
\hline
\end{tabular}

cell types. Lactate also decreased in $21 \% \mathrm{O}_{2}$ in high glucose medium for RAS cells.

The total amount of lactate produced to glucose consumed ratio $(\Delta \mathrm{L} / \Delta \mathrm{G})$ varied with condition and cell type over time (table 1 ). At day $1, \Delta \mathrm{L} / \Delta \mathrm{G}$ ratio remained near 2 in the high glucose medium for both oxygen tensions. This ratio was lower in low glucose medium, but more so in 21 than $1 \% \mathrm{O}_{2}$. At day 7 , the $\Delta \mathrm{L} / \Delta \mathrm{G}$ ratio decreased for most conditions. The lowest $\Delta \mathrm{L} / \Delta \mathrm{G}$ ratio occurred in $21 \% \mathrm{O}_{2}$ in low glucose medium. Lower $\Delta \mathrm{L} / \Delta \mathrm{G}$ ratios were also found in $21 \% \mathrm{O}_{2}$ and high glucose and $1 \% \mathrm{O}_{2}$ and low glucose. The $\Delta \mathrm{L} / \Delta \mathrm{G}$ ratio in $1 \% \mathrm{O}_{2}$ and high glucose changed little from day 1 .

\section{Discussion}

When testing a hypothesis regarding a cellular response to reduced oxygen and nutrient levels, it is important to characterize metabolism under the experimental conditions and understand how this relates to the in vivo environment. In the case of primary open angle glaucoma, several potential mechanisms could result in reduced nutrient and oxygen levels as well as the observed remodeling of the lamina cribrosa connective tissue. Two cell populations are believed to maintain the lamina cribrosa: lamina cribrosa cells and astrocytes. Lamina cribrosa cells are connective tissue cells believed to differ from scleral fibroblasts [Clark et al., 1995]. For this reason, we designed this study to compare all 3 cell types to determine their response to stressful culture conditions. This was achieved by measuring the amounts of glucose, lactate, pyruvate and glutamate remaining in the medium over 7 days for 4 different culture conditions and 3 dif- 
ferent cell types. The 4 culture conditions examined were $1 \% \mathrm{O}_{2}$ and high glucose, $1 \% \mathrm{O}_{2}$ and low glucose, $21 \% \mathrm{O}_{2}$ and high glucose as well as $21 \% \mathrm{O}_{2}$ and low glucose. These data will provide a baseline for the further development of in vitro models of the optic nerve head. Such models will help elucidate the interaction between mechanical loading and the often concomitant decrease in nutrient transport.

The concentration of several metabolites in the medium changed over the course of the experiment. Glucose levels decreased in a manner dependent on the oxygen level and the cell number. More glucose remained at the same time points in $21 \% \mathrm{O}_{2}$ compared to $1 \% \mathrm{O}_{2}$ even though more cells were present in 21 than $1 \% \mathrm{O}_{2}$. This suggests that in $21 \% \mathrm{O}_{2}$ some fraction of glucose was utilized aerobically. Between cell types, more glucose remained in PSC than in PLC or RAS culture medium at the same time points. Due to the nature of the experiment, it was not possible to properly normalize glucose consumption to cell number so that direct comparisons in glucose utilization could be made. However, lower PSC cell numbers relative to the other cell types over the course of the experiment suggest that cell number was the principal reason why glucose remained in PSC cultures longer. Interestingly, the transformed RAS cells were the only group to exhibit a dependence on oxygen, although this too was likely a function of cell number.

Glutamate levels remained low or nonexistent over the course of the experiment. However, without knowledge of glutamine levels, it is difficult to interpret these results. Both low and high glucose medium initially contained 4 $\mathrm{mM}$ glutamine. But glutamine is unstable and spontaneously deaminates into glutamate over time. Glutamine is either incorporated directly into anabolic events or utilized metabolically, where it is converted to glutamate and proceeds through the tricarboxylic acid cycle (TCA). Furthermore, some reports suggest that when glucose levels are low, glutamine becomes the primary energy source [Zielke et al., 1978].

Pyruvate levels fluctuated near the initial concentration of $1 \mathrm{mM}$ for much of the experiment. The greatest decrease in pyruvate coincided with conditions where no glucose remained and sufficient oxygen was available (low glucose $21 \% \mathrm{O}_{2}$ day 7). Consumption of pyruvate through the TCA cycle seems the most likely explanation for the decrease under these conditions.

High levels of lactate were produced for all conditions, indicating that once glucose had proceeded through glycolysis, the majority of pyruvate was converted to lactate rather than oxidatively metabolized through the TCA cy- cle and oxidative phosphorylation. Higher lactate levels were produced in 1 than $21 \% \mathrm{O}_{2}$, lending further support to the notion that some glucose was utilized aerobically. Furthermore, lactate levels at later time points began to decline in $21 \% \mathrm{O}_{2}$ when glucose was absent, suggesting that the cells were forced to consume the lactate aerobically. This same response was not apparent in $1 \% \mathrm{O}_{2}$. Cell micrographs (data not shown) at this oxygen level show cell death occurring by day 7 , suggesting that not enough oxygen was available to sustain the cells through aerobic respiration. Higher $\Delta \mathrm{L} / \Delta \mathrm{G}$ ratios were found in high glucose medium compared to low glucose medium at day 1. In addition, a greater reduction in this ratio occurred at day 7 in 21 than $1 \% \mathrm{O}_{2}$, indicating that, while reduction to lactate dominated, more glucose was oxidatively metabolized by cells in $21 \% \mathrm{O}_{2}$.

The results of this study are consistent with reports in the literature [Neermann and Wagner, 1996; Gstraunthaler et al., 1999; Obradovic et al., 1999; Europa et al., 2000]. High glucose levels often result in higher glucose consumption rates with $80-90 \%$ conversion to lactate [Europa et al., 2000]. At lower glucose levels there is a reduction in the glucose consumption rate, and a larger fraction of the glucose is completely oxidized to carbon dioxide if enough oxygen is present [Zielke et al., 1978; Europa et al., 2000]. At very low glucose concentrations the glucose consumption rate and the $\Delta \mathrm{L} / \Delta \mathrm{G}$ ratio decrease, but the specific oxygen consumption rate increases [Hu and Oberg, 1990]. Furthermore, once glucose levels are depleted, lactate is reutilized in an oxygen-dependent manner [Gstraunthaler et al., 1999].

Many in vitro cell cultures primarily derive energy from glucose through glycolysis rather than complete oxidation through TCA and oxidative phosphorylation for reasons that remain unknown. Brand [1997] proposed that the transition to aerobic glycolysis, a term referring to the degradation of glucose to lactate in the presence of oxygen, reduces mitochondrial glucose oxidation and protects the cells against oxidative stress during critical phases of biosynthesis and cell division. Since the vast majority of cell cultures involve maintaining proliferating cells, this hypothesis would explain why aerobic glycolysis dominates respiration.

Restoration of aerobic respiration to in vivo levels is a necessary step towards developing more representative in vitro culture models. Several studies have reported that the effects of changing certain culture parameters affected the $\Delta \mathrm{L} / \Delta \mathrm{G}$ ratio. For example, Obradovic et al. [1999] found that chondrocytes cultured on polymer scaffolds in a rotating bioreactor predominantly respired anaero- 
bically, although to a lesser extent in $21 \% \mathrm{O}_{2}(\Delta \mathrm{L} / \Delta \mathrm{G}$ 1.65-1.79) compared to $5 \% \mathrm{O}_{2}(\Delta \mathrm{L} / \Delta \mathrm{G} 2.2)$. When medium was replaced less frequently, a reduction in glucose consumption and lactate production was observed. Gstraunthaler et al. [1999] improved $\Delta \mathrm{L} / \Delta \mathrm{G}$ by decreasing the medium height or using roller bottles to improve oxygenation in their renal epithelial cultures. Europa et al. [2000] significantly reduced MAK cell lactate production by reducing glucose levels. An initial glucose concentration of $556 \mu \mathrm{M}$ maintained at a set point of $277 \mu \mathrm{M}$ in fed-batch culture resulted in a $\Delta \mathrm{L} / \Delta \mathrm{G}$ of 0.21 approximately $105 \mathrm{~h}$ after the start of the experiment and coinciding with when the cells had passed the exponential growth period. Continuous culture was initiated further reducing $\Delta \mathrm{L} / \Delta \mathrm{G}$ to a steady state value of 0.04 , a marked improvement from $\Delta \mathrm{L} / \Delta \mathrm{G}$ of 1.36 for the control.

PLC and PSC cells were isolated from tissues obtained within $6 \mathrm{~h}$ of animal death. Even though the eyes were kept on ice until the isolation process could begin, cells within the tissue were subjected to a nonphysiological environment for several hours. Thus, the cells obtained could represent a subpopulation of stress-resistant cells atypical of the population in the optic nerve head. Most studies in the field, including the seminal study of Hernandez et al. [1988], in which lamina cribrosa cells were first identified, isolated the cells from tissues with even longer harvest times (for example, $8 \mathrm{~h}$ [Hernandez et al.,
1988] and $24 \mathrm{~h}$ [Lambert et al., 2001]). The astrocytes used in this study were obtained from an established cell line, and were not subjected to the stresses from harvest. The astrocytes followed the same trends as PLC and PSC cells, suggesting that if stress-resistant cells were harvested, they responded in the same manner as an established cell line.

The results of this study demonstrated that our current in vitro model does not reflect in vivo cellular metabolism. All 3 cell types predominantly utilized glucose through aerobic glycolysis. Immediate improvements should be possible by reducing the glucose concentration in the medium, switching to a fed-batch operation where medium is replaced on a regular basis, and bringing the cultures to a nonproliferative steady state. Better oxygenation may be necessary but caution should be exercised to maintain levels below the point of toxicity. Once these medium parameters have been optimized to reduce $\Delta \mathrm{L} / \Delta \mathrm{G}$ to aerobic levels, the effect of low oxygen on the response of cells can then be explored.

\section{Acknowledgement}

This work was supported by the Louisiana Board of Regents and NIH grant 1RO3 EY 14135-01.

\section{References}

Bellezza, A.J., R.T. Hart, C.F. Burgoyne (2000) The optic nerve head as a biomechanical structure: initial finite element modeling. Invest Ophthalmol Vis Sci 41: 2991-3000.

Bergmeyer, H.U. (1983) Methods of Enzymatic Analysis. Weinheim, Verlag Chemie.

Blaheta, R.A., M. Franz, M.K. Auth, H.J. Wenisch, B.H. Markus (1991) A rapid nonradioactive fluorescence assay for the measurement of both cell number and proliferation. J Immunol Methods 142: 199-206.

Brand, K. (1997) Aerobic glycolysis by proliferating cells: protection against oxidative stress at the expense of energy yield. J Bioenerg Biomembr 29: 355-364.

Burgoyne, C.F., J.C. Downs, A.J. Bellezza, J.K. Suh, R.T. Hart (2005) The optic nerve head as a biomechanical structure: a new paradigm for understanding the role of IOP-related stress and strain in the pathophysiology of glaucomatous optic nerve head damage. Prog Retin Eye Res 24: 39-73.
Cardinal, K.O., G.T. Bonnema, H. Hofer, J.K. Barton, S.K. Williams (2006) Tissue-engineered vascular grafts as in vitro blood vessel mimics for the evaluation of endothelialization of intravascular devices. Tissue Eng 12: 3431-3438.

Clark, A.F., S. Browder, H.T. Steely, K. Wilson, D. Cantu-Crouch, M.D. McCartney (1995) Cell biology of the human lamina cribrosa; in Drance, S.M. (ed): Optic Nerve in Glaucoma. Amsterdam, Kugler, pp 79-105.

Csete, M. (2005) Oxygen in the cultivation of stem cells. Ann NY Acad Sci 1049: 1-8.

Europa, A.F., A. Gambhir, P.C. Fu, W.S. Hu (2000) Multiple steady states with distinct cellular metabolism in continuous culture of mammalian cells. Biotechnol Bioeng 67: 2534.

Fermor, B., J. Urban, D. Murray, A. Pocock, E. Lim, M. Francis, J. Gage (1998) Proliferation and collagen synthesis of human anterior cruciate ligament cells in vitro: effects of ascorbate-2-phosphate, dexamethasone and oxygen tension. Cell Biol Int 22: 635-640.
Foster, D.W., A.H. Rubenstein (1994) Hypoglycemia; in Isselbacher, K.J., E. Braunwald, J.D. Wilson, J.B. Martin, A.S. Fauci, D.L. Kasper (eds): Harrison's Principles of Internal Medicine. New York, McGraw-Hill, pp 20002006.

Freshney, R.I. (2000) Culture of Animal Cells: A Manual of Basic Technique. New York, Wiley-Liss.

Griffith, L.G., G. Naughton (2002) Tissue engineering - current challenges and expanding opportunities. Science 295: 1009-1014.

- Gstraunthaler, G., T. Seppi, W. Pfaller (1999) Impact of culture conditions, culture media volumes, and glucose content on metabolic properties of renal epithelial cell cultures. Are renal cells in tissue culture hypoxic? Cell Physiol Biochem 9: 150-172.

Hansen, U., M. Schunke, C. Domm, N. Ioannidis, J. Hassenpflug, T. Gehrke, B. Kurz (2001) Combination of reduced oxygen tension and intermittent hydrostatic pressure: a useful tool in articular cartilage tissue engineering. J Biomech 34: 941-949. 
Hernandez, M.R. (2000) The optic nerve head in glaucoma: role of astrocytes in tissue remodeling. Prog Retin Eye Res 19: 297-321.

Hernandez, M.R., F. Igoe, A.H. Neufeld (1988) Cell culture of the human lamina cribrosa. Invest Ophthalmol Vis Sci 29: 78-89.

-Hernandez, M.R., X.X. Luo, W. Andrzejewska, A.H. Neufeld (1989) Age-related changes in the extracellular matrix of the human optic nerve head. Am J Ophthalmol 107: 476484.

Hu, W.S., M.G. Oberg (1990) Monitoring and control of animal cell bioreactors: Biochemical engineering considerations. Bioprocess Technol 10: 451-481.

Ignatius, A., H. Blessing, A. Liedert, C. Schmidt, C. Neidlinger-Wilke, C. Kaspar, B. Friemert, L. Claes (2005) Tissue engineering of bone: effects of mechanical strain on osteoblastic cells in type I collagen matrices. Biomaterials 26: 311-318.

Lambert, W., R. Agarwal, W. Howe, A.F. Clark, R.J. Wordinger (2001) Neurotrophin and neurotrophin receptor expression by cells of the human lamina cribrosa. Invest Ophthalmol Vis Sci 42: 2315-2323.

- Neermann, J., R. Wagner (1996) Comparative analysis of glucose and glutamine metabolism in transformed mammalian cell lines, insect and primary liver cells. J Cell Physiol 166: 152-169.
Obradovic, B., R.L. Carrier, G. Vunjak-Novakovic, L.E. Freed (1999) Gas exchange is essential for bioreactor cultivation of tissue engineered cartilage. Biotechnol Bioeng 63: 197-205.

Planchet, E., K. Jagadis Gupta, M. Sonoda, W.M Kaiser (2005) Nitric oxide emission from tobacco leaves and cell suspensions: Rate limiting factors and evidence for the involvement of mitochondrial electron transport. Plant J 41: 732-743.

Richards, W.L., M.K. Song, H. Krutzsch, R.P. Evarts, E. Marsden, S.S. Thorgeirsson (1985) Measurement of cell proliferation in microculture using Hoechst 33342 for the rapid semiautomated microfluorimetric determination of chromatin DNA. Exp Cell Res 159: 235-246.

Shimko, D.A., K.K. White, E.A. Nauman, K.C. Dee (2003) A device for long term, in vitro loading of three-dimensional natural and engineered tissues. Ann Biomed Eng 31: 1347-1356.
Sivaraman, A., J.K. Leach, S. Townsend, T. Iida, B.J. Hogan, D.B. Stolz, R. Fry, L.D. Samson, S.R. Tannenbaum, L.G. Griffith (2005) A microscale in vitro physiological model of the liver: Predictive screens for drug metabolism and enzyme induction. Curr Drug Metab 6: 569-591.

Smith, M.K., D.J. Mooney (2007) Hypoxia leads to necrotic hepatocyte death. J Biomed Mater Res A 80: 520-529.

-Stefansson, E., M.B. Landers 3rd, M. Wolbarsht (2005a) Retinal vessel caliber and diabetic retinopathy. Arch Ophthalmol 123: 709.

- Stefansson, E., D.B. Pedersen, P.K. Jensen, M. la Cour, J.F. Kiilgaard, K. Bang, T. Eysteinsson (2005b) Optic nerve oxygenation. Prog Retin Eye Res 24: 307-332.

Suuronen, E.J., C.R. McLaughlin, P.K. Stys, M. Nakamura, R. Munger, M. Griffith (2004) Functional innervation in tissue engineered models for in vitro study and testing purposes. Toxicol Sci 82: 525-533.

-Tjabringa, G., M. Bergers, D. van Rens, R. de Boer, E. Lamme, J. Schalkwijk (2008) Development and validation of human psoriatic skin equivalents. Am J Pathol 173: 815-823.

-Zielke, H.R., P.T. Ozand, J.T. Tildon, D.A. Sevdalian, M. Cornblath (1978) Reciprocal regulation of glucose and glutamine utilization by cultured human diploid fibroblasts. J Cell Physiol 95: 41-48. 